\title{
STUDI LABORATORIUM PEMILIHAN ADDITIF PENSTABIL SHALE DI DALAM SISTEM LUMPUR KCL-POLIMER PADA TEMPERATUR TINGGI
}

\author{
Zakky, Bayu Satyawira, Samsol \\ Program Studi Teknik Perminyakan - Universitas Trisakti \\ samsol@trisakti.ac.id
}

\begin{abstract}
Mud is one of the things that is very supportive in drilling operations, the design of the mud can affect the effectiveness of drilling work, the costs to be incurred, up to when the well is in production. Of course what is expected from a mud usage is low expenditure and drilling with optimal results. Drilling mud plays a very important role in a drilling operation. Drilling that can run quickly, safely and economically is greatly influenced by the conditions and sludge system used. The condition referred to here is how the properties or rheology of the mud. Whereas the mud system referred to here is a certain type of mud that must be used with regard to the state of the formation and borehole. Muddy $K C l-P O L Y M E R$ is a non-dispersed mud, where the hydration and dispersion process of the shale formation drilled must be maintained or maintained as much as possible. There are several ways to achieve this, the most common of which is to limit the amount of water that reacts with the shale, by covering the cutting produced by the shale with the polymer as soon as possible to prevent further reactions with water. In this study, we will analyze the use and physical properties of drilling mud using KCl-Polymer sludge which is carried out in the Trisakti University Laboratory of Petroleum Drilling and Production.
\end{abstract}

\begin{abstract}
Abstrak
Lumpur merupakan salah satu hal yang sangat menunjang di dalam operasi pemboran, desain lumpur tersebut dapat mempengaruhi efektifitas kerja pemboran, biaya yang akan dikeluarkan, sampai kepada saat sumur itu telah berproduksi. Tentu yang diharapkan dari suatu penggunaan lumpur adalah pengeluaran yang rendah dan melakukan pemboran dengan hasil yang optimal. Lumpur pemboran memegang peranan yang sangat penting di dalam suatu operasi pemboran. Pemboran yang dapat berjalan dengan cepat, aman, dan ekonomis, sangat dipengaruhi oleh kondisi dan sistem lumpur yang digunakan. Kondisi yang dimaksud disini adalah bagaimana sifatsifat atau rheologi dari lumpur tersebut. Sedangkan sistem lumpur yang dimaksud disini adalah lumpur jenis tertentu yang harus digunakan dengan memperhatikan keadaan formasi dan lubang bor.Lumpur KCl-POLIMER merupakan lumpur non disperse, dimana proses hidrasi dan dispersi dari formasi shale yang dibor harus dijaga atau dipertahankan semaksimal mungkin. Ada beberapa cara untuk mencapai hal ini, yang paling umum adalah dengan cara membatasi jumlah air yang bereaksi dengan shale, dengan cara menyelimuti cutting yang dihasilkan oleh shale dengan polimer sesegera mungkin untuk mencegah reaksi lebih lanjut dengan air. Pada penelitian ini akan menganalisa penggunaan serta sifat - sifat fisik lumpur pemboran menggunakan lumpur $\mathrm{KCl}$-Polimer yang dilakukan di Laboratorium Pemboran dan Produksi Teknik Perminyakan Universitas Trisakti.
\end{abstract}

\section{Pendahuluan}

Lumpur Pemboran merupakan bagian dari kegiatan pencarian minyak dan gas bumi yang dilakukan baik pada saat eksplorasi maupun saat pengembangan. Lumpur pemboran mempunyai peranan yang sangat penting serta merupakan salah satu komponen utama yang menentukan kelancaran dan keberhasilan suatu operasi pemboran. Sistem lumpur yang digunakan pada suatu operasi pemboran harus disesuaikan dengan kondisi formasi serta litologi batuan yang ditembus. Hal ini dimaksudkan agar lumpur pemboran tersebut dapat berfungsi dengan baik serta dapat mencegah dan menanggulangi problem-problem yang terjadi. Lumpur pemboran berkembang pesat dengan ditemukannya jenis - jenis lumpur pemboran dengan karakteristik yang sangat berbeda satu dengan yang lainnya, sebagai akibat dari semakin berkembangnya aditif yang dapat dipergunakan untuk menjaga kestabilan lumpur pemboran pada kedalaman yang berbeda, salah satunya adalah lumpur $\mathrm{KCl}$-Polimer. Keuntungan utama pemakaian KCl-Polimer zat-zat ini dapat 
mencapai viskositas maksimum dengan kandungan padatan yang minimum. Lumpur ini tergolong sistem penghambat (inhibitif) terhadap shale dan tidak terdispersi (nondispersed). Fungsi utama dari k-soltex adalah menstabilkan sifat fisik lumpur KCl-polimer didalam temperatur tinggi. Dengan ditemukannya lumpur polimer ini, maka dihasilkan suatu solusi yang lebih efektif bagi biaya operasi pemboran. Adapun peralatan yang digunakan antara lain adalah Mud Balance, Fann VG Meter, Marsh Funnel, API Filtration, Kertas Lakmus, Cawan Titrasi, Methylene Blue Test Kit yang terdapat di Laboratorium Lumpur Pemboran dan Produksi Teknik Perminyakan Universitas Trisakti. Pada penulisan skripsi ini, Penulis memilih judul "Studi Laboratorium Pemilihan Additif Penstabil Shale di Dalam Sistem Lumpur KCL-Polimer pada Suhu Tinggi”.

\section{Problem Statement}

Pada Penelitian ini dilakukan pengamatan mengenai pengaruh yang terjadi pada lumpur ketika mengalami kontaminasi oleh serpihan serbuk bor, serta perubahan temperature yang terjadi pada saat menembus kedalaman kedalaman yang berbeda saat melakukan pemboran. Dilakukan pengamatan perubahan parameter sifat fisik dan rheologi lumpur guna memepelajari penanggulangan yang dapat dilakukan untuk menjaga lumpur agar tetap dapat berfungsi dengan temperatur formasi yang berubah menjadi lebih tinggi.

\section{Teori Dasar}

Densitas atau berat jenis sangat penting diketahui untuk menentukan besarnya tekanan hidrostatik kolom lumpur untuk tiap kedalaman. Lumpur harus dikontrol agar dapat memberikan tekanan hidrostatik yang cukup untuk mencegah masuknya cairan formasi kedalam lubang bor, tetapi tekanan tersebut tidak boleh terlalu besar karena akan mengakibatkan formasi pecah dan lumpur hilang kedalam formasi. Oleh karena itu berat jenis Lumpur pemboran perlu direncanakan sebaik-baiknya dan disesuaikan dengan keadaan tekanan formasi. Densitas suatu fluida adalah berat fluida dibagi volumenya pada temperatur dan tekanan tertentu. Satuan dimensi yang dipakai adalah $\mathrm{kg} / \mathrm{l}, \mathrm{gr} / \mathrm{cc}$ dan lb/gal. Densitas lumpur adalah berat lumpur dibagi dengan volume lumpur atau dapat dinyatakan dengan persamaan berikut :

$$
S G=\frac{\rho m}{\text { pair }}
$$

$$
\begin{aligned}
& \text { Dimana: } \\
& \mathrm{SG} \quad=\text { Spesific Gravity } \\
& \mathrm{\rho m} \quad=\text { Densitas Lumpur, } \mathrm{ppg} \\
& \text { pair } \quad=\text { Densitas air, } \mathrm{ppg}
\end{aligned}
$$

Tekanan hidrostatik lumpur di dasar lubang adalah fungsi dari berat jenis lumpur itu sendiri. Tekanan hidrostatik lumpur di dasar lubang akan mempengaruhi kemampuan dari pada formasi di bawahnya yang akan dibor. Di lapangan berat jenis lumpur diukur dengan menggunakan suatu alat yang disebut mud balance. Semakin besar tekanan hidrostatik lumpur maka akan semakin mampat dan hal ini merupakan hambatan pahat untuk mengoreknya. Oleh karena itu, maka kita harus menjaga tekanan hidrostatik dari lumpur agar stabil, sehingga tekanan hidrostatik lumpur tidak terlalu besar dan tidak terlalu kecil. Viskositas adalah tahanan fluida terhadap aliran atau gerakan yang disebabkan oleh adanya gesekan antara partikel pada fluida yang mengalir, yang mana disebabkan oleh adanya pergeseran antara :

- Partikel-partikel itu sendiri.

- Partikel-partikel padatan itu sendiri.

- Partikel padatan dengan molekul zat cair.

- Molekul-molekul zat cair. 
Pada lumpur bor, viskositas merupakan suatu tahanan terhadap aliran lumpur yang memegang peranan dalam pengangkatan serbuk bor ke permukaan. Semakin kental lumpur maka pengangkatan cutting makin baik. Apabila lumpur tidak cukup kental maka pengangkatan serbuk bor kurang sempurna dan akan mengakibatkan serbuk bor tertinggal didalam lubang bor sehingga menyebabkan rangkaian pipa pemboran akan terjepit. Akan tetapi apabila lumpur mempunyai viskositas yang besar sekali maka akan dapat mengakibatkan problem pada pemisahan cutting permukaan. Menurut Poiseille, viskositas lumpur dapat dinyatakan dengan persamaan berikut:

$$
\mu=\frac{\text { ShearStress }}{\text { Shear Rate }}=\frac{F / A}{V / r}
$$

Dimana:

$$
\begin{array}{ll}
\mathrm{M} & =\text { Viskositas, } \mathrm{cp} \\
\mathrm{F} & =\text { Gaya yang bekerja pada Sistem, dyne } \\
\mathrm{A} & \text { = Luas penampang, } \mathrm{cm} / \mathrm{det} \\
\mathrm{V} & =\text { Kecepatan alir, } \mathrm{cm} / \mathrm{det} \\
\mathrm{R} & \text { = Jarak aliran, } \mathrm{cm}
\end{array}
$$

jadi, viskositas merupakan faktor perbandingan antara shear stress (tegangan geser) dengan shear rate (laju pegeseran). Selain itu Poiseille juga menyatakan:

Jika viskositas konstan dan berupa garis lurus (tidak berubah shear stress dan shear rate nya) maka fluida tersebut dinamakan "Newtonian Fluida"

Jika viskositas berubah terhadap shear rate, maka fluida tersebut dinamakan "Non Newtonian Fluida" seperti pada gambar 2.3.

Sedangkan lumpur merupakan fluida Non Newtonian. Pada fluida Non Newtonian dikenal dengan adanya plastic viscosity, yield point dan apparent viscosity. Plastic viscosity adalah suatu tahanan terhadap aliran yang disebabkan oleh adanya gesekan-gesekan antara padatan dalam lumpur, padatan cairan dan gesekan antara lapisan cairan, dimana plastic viscosity merupakan hasil torsi dari pembacaan pada alat viscometer. Torsi pada putaran $600 \mathrm{rpm}$ dikurangi torsi pada putaran $300 \mathrm{rpm}$, yield point adalah gaya elektro kimia antara padatan-padatan, cairan-cairan, cairan-padatan pada zat kimia dalam kondisi dinamis yang berhubungan dengan pola aliran, pengangkatan serpih, kehilangan tekanan di annular dan kontaminasi.

Yield point merupakan hasil dari torsi pada putaran 300 rpm dikurangi plastic viscosity, sedangkan apparent viscosity adalah keadaan dimana fluida Non Newtonian, dimana apparent viscosity merupakan hasil torsi pada putaran $600 \mathrm{rpm}$ dibagi dua dan dapat ditulis dengan persamaan sebagai berikut:

$$
\begin{aligned}
\mathrm{PV} & =\theta_{500}-\theta_{300} \\
\mathrm{YP} & =\theta_{500}-\mathrm{PV} \\
\mathrm{AV} & =\frac{\theta_{03}}{2}
\end{aligned}
$$

dimana:

$$
\begin{aligned}
& \text { PV } \quad \text { Plastic Viscosity }, \mathrm{cp} \\
& \mathrm{YP}=\text { Yield Point, } \mathrm{lbs} / 100 \mathrm{ft}^{2} \\
& \mathrm{AV} \quad=\text { Apparent Viscosity, } \mathrm{lbs} / 100 \mathrm{ft}^{2}
\end{aligned}
$$

Didalam operasi pemboran seringkali viskositas lumpur naik, hal ini disebabkan karena:

$$
\text { Flokulasi (penggumpalan) }
$$

\footnotetext{
- Padatan-padatan tertentu didalam lumpur
} 
Yield Point merupakan angka yang menunjukan shearing stress yang diperlukan untuk mensirkulasi lumpur kembali, dengan kata lain lumpur tidak akan dapat bersikulasi sebelum diberikan shearing stress sebesar yield point. Yield point sangat penting diketahui untuk perhitungan hidrolika lumpur, dimana yield point mempengaruhi tekanan diwaktu lumpur bersirkulasi. Untuk dapat menentukan yield point lumpur bor dapat digunakan Stromer Viscometer ataupun Fann VG Meter.

\section{Hasil dan Pembahasan}

Lumpur KCl-Polimer yang digunakan pada analisa di laboratorium ini adalah jenis lumpur berbahan dasar air (Fresh Water). Tujuan dari penelitian ini adalah untuk melihat pengaruh penambahan additif Penstabil shale secara bertahap pada sistem lumpur $\mathrm{KCl}$ Polimer, terhadap pengukuran rheologi lumpur pada berbagai temperatur pengukuran. Pada percobaan ini lumpur $\mathrm{KCl}$-Polimer yang berbahan dasar air (fresh water) diberikan penambahan additif penstabil shale dan dipanaskan dengan Thermo cup, dimana, pada setiap pemakaian lumpur tersebut ada penambahan additif penstabil shale dan kemudian dilakukan penambahan shale sebesar $5 \mathrm{gr}$ pada setiap komposisi yang ada. Kemudian lumpur yang sudah dibuat dimasukan kedalam Thermo cup dan diproses dengan temperatur mulai dari $80^{\circ} \mathrm{F}$ (ruang), $180^{\circ} \mathrm{F}$, dan $280^{\circ} \mathrm{F}$. Hasil dari pengamatan kemudian dibandingkan dengan standar spesifikasi lumpur pengeboran. Pada percobaan ini dibagi dalam 2 komposisi lumpur dengan penambahan additf penstabil shale dan 1 komposisi lumpur dasar, dengan komposisi L.D dengan bahan fresh water 336,6 ml, soda ash 0,3 gr, bentonite 12,5 gr, KOH 1,5 gr, KCL 10,5 gr, Pac-LV 2 gr, dan Pac-HV 2,5 gr. Untuk komposisi L.A1 bahan yang digunakan hampir sama dengan komposisi yg digunakan pada komposisi L.D hanya saja ada perbedaan pada konsentrasi fresh water menjadi 335,39 ml, dan penambahan k-soltex 1, 3, 5 gr. Kemudian untuk komposisi L.B1 coba menaikkan konsentrasi fresh water menjadi 333,6 ml, duranex 1, 3, $5 \mathrm{gr}$. Yang masingmasing lumpur tersebut kemudian mengalami perubahan temperatur yang hasil pengujian ini kemudian dibuat menjadi grafik untuk membandingkan perubahan sifat fisik lumpur sistem lumpur tersebut dengan temperatur pengukuran. Densitas lumpur pemboran merupakan salah satu sifat lumpur yang sangat berpengaruh karena peranannya yang berhubungan langsung dengan fungsi lumpur sebagai penahan tekanan formasi. Adanya densitas lumpur pemboran yang terlalu besar dapat mengakibatkan lumpur hilang ke dalam formasi (Loss Circulation). Sedangkan jika terlalu kecil maka akan menimbulkan semburan liar (Blow Out). Sehingga densitas lumpur harus disesuaikan dengan keadaan formasi yang akan ditembus Dari hasil pengujian dari Plastic Viscosity (PV). Harga plastic viscosity ini didapat dari pengurangan antara viscosity dial reading $\Theta 600$ dengan viscosity dial reading $\Theta 300$. Harga PV standar API adalah 8-18 $\mathrm{cp}$. Didapat komposisi yang bagus pada komposisi L.B2 karena tahan terhadap temperatur tinggiHasil pengujian Yield Point (YP) untuk masing-masing komposisi , harga YP didapat dari hasil pengurangan antara dial reading $\Theta 300$ dengan PV. Harga YP sesuai standar API adalah 9-13 $\mathrm{lb} / 100 \mathrm{ft}^{2}$. Berdasarkan tabel hasil pengukuran maka dapat dilihat komposisi yang sesuai dengan standar API pada temperatur tinggi adalah komposisi L.B2. Yield point untuk masing masing temperatur untuk komposisi L.D, L.A1, L.A2, L.A3, L.B1, dan L.B3 tidak dapat digunakan karena mempunyai nilai yang tidak sampai standar spesifikasi lumpur

pemboran dengan nilai 8 dan $7 \mathrm{lbs} / 100 \mathrm{ft}^{2}$ pada suhu 130 dan $180{ }^{\circ} \mathrm{F}$ Gel Strength 10 detik untuk lumpur L.D, L.A1, L.A2, LA3 hanya baik pada temperatur $280^{\circ} \mathrm{F}$ dengan harga berkisar antara 6 hingga 4. Sedangkan untuk komposisi L.B1 dan L.B2 adalah yang paling baik digunakan karena memenuhi standar lumpur pemboran dengan harga berkisar antara 2,5 hingga 2 pada temperatur $80^{\circ} \mathrm{F}$ sampai $280{ }^{\circ} \mathrm{F}$. Apabila temperatur dinaikkan maka harga Gel Strength akan turun dan akan mempengaruhi sirkulasi lumpur karena daya tahannya berkurang. Laju tapisan lumpur ini untuk semua komposisi lumpur yang ujikan ada yang tidak dapat digunakan karena laju tapisannya terlalu besar dan hanya mampu bertahan pada temperatur 230 sampai $280^{\circ} \mathrm{F}$ (ruang) pada lumpur L.B1. Sedangkan untuk komposisi L.D, L.A1, L.A2, L.A3, L.B2, dan L.B3 dapat bertahan pada batas optimal water loss sesuai dengan standar spesifikasi yang digunakan untuk system lumpur additif penstabil shale Hasil penelitian mud cake pada lumpur ini menunjukkan 
kenaikan harga mud cake, akan tetapi kendati water loss tinggi, maka semua komposisi dapat digunakan hingga temperatur $280^{\circ} \mathrm{F}$ dengan harga kisaran 1 sampai $2,2 \mathrm{~mm}$, yang memenuhi batas standar harga mud cake lumpur pemboran yaitu $\leq 2,5 \mathrm{~mm}$ pH lumpur dengan dinaikkannya temperatur terjadi penurunan harga $\mathrm{pH}$ pada masing masing

komposisi, komposisi L.A1, L.A3, L.B1, dan L.B3 tidak dapat digunakan karena tidak memenuhi batas standar harga $\mathrm{pH}$, sedangkan komposisi L.D, L.A2 dan L.B2 memiliki komposisi yang ideal sesuai batas standar harga $\mathrm{pH}$, yaitu 9 hingga 10 pada $280^{\circ} \mathrm{F}$.

\section{Kesimpulan dan Saran}

Dari analisa studi laboratorium penggunaan lumpur additif penstabil shale untuk mengatasi shale aktif, dapat diambil beberapa kesimpulan sebagai berikut:

1. Pengukuran densitas terjadi penurunan untuk setiap komposisi sesuai dengan kenaikan temperatur, dengan harga yaitu antara 8,8 hingga 8,5 ppg sehingga semua komposisi lumpur dapat digunakan dari temperatur ruang $80^{\circ} \mathrm{F}$ sampai temperatur $280^{0} \mathrm{~F}$.

2. Pengukuran pada Plastic Viscosity terjadi penurunan untuk setiap komposisinya, dengan standar spesifikasi lumpur pada laboratorium 8 - $18 \mathrm{Cp}$ maka yang memenuhi syarat adalah L.B2 , karena mempunyai harga yang mampu bertahan pada temperatur $280^{\circ} \mathrm{F}$.

3. Untuk Yield Point yang masuk dalam spesifikasi standar lumpur ideal antara 9 hingga $13 \mathrm{lb} / 100 \mathrm{ft}^{2}$, yaitu komposisi lumpur L.B2 pada temperatur 80 hingga $280^{\circ} \mathrm{F}$.

4. Pengukuran Gel Strength 10 detik untuk lumpur additif penstabil shale, komposisi L.B1 dan L.B2 yang masuk dalam spesifikasi standar lumpur karena mampu bertahan dari temperatur $80{ }^{\circ} \mathrm{F}$ sampai temperatur $280^{\circ} \mathrm{F}$ dengan harga antara 2 hingga $7 \mathrm{lb} / 100 \mathrm{ft}^{2}$. Pengukuran Gel Strength 10 menit untuk lumpur additif penstabil shale, komposisi L.B2 yang memenuhi standar lumpur ideal antara 10 hingga 18 $\mathrm{lb} / 100 \mathrm{ft}^{2}$ dari temperature $80^{\circ} \mathrm{F}$ sampai temperatur $280^{0} \mathrm{~F}$.

\section{Daftar Pustaka}

El Bialy, M et.al, "Utilization of Non-damaging Drilling Fluid Composed of Potassium Formated Brine and Manganese Tetra Oxide to Drill Sandstone Formation in Tight Gas Reservoir", SPE/IADC Middle East Drilling Technology Conference and Exhibition, 2011.

Growcock, Frederick B And Patel, Arvin D, "The Revolution in Non-Aqueous Drilling Fluids", AADE National Technical Conference and Exhibition, 2011.

Adebayo, Thomas A and Balogun, Omotola, "Alteration of oil-Based Drilling Mud Properties Due to Contact with CO2 Gas Kick During Drilling", 2011.

Diktat Kuliah Teknik Pemboran I, Universitas Trisakti.

Laboratorium Teknik Pemboran dan Produksi, "Penuntun Praktikum Lumpur Pemboran", 1980.

Rismanto, Rizal and van der Zwaag, Claas, "Explorative Study of NMR Drilling Fluids Measurement", Annual Transactions of the Nordic Rheology Society vol. 15, 2007.

Sadya, Robani, “Diktat Kuliah Teknik Lumpur Pemboran”, Universitas Trisakti, 1984.

McFadyen, Mike et.al, "New Synthetic Fluid System Provides Stable Cold-Temperature Rheologies", 2002. 